\title{
RANCANG BANGUN SISTEM INFORMASI KULIAH KERJA NYATA (KKN) PADA UNIVERSITAS MURIA KUDUS
}

\author{
Galuh Fandatiar \\ Fakultas Teknik, Program Studi Sistem Informasi \\ Universitas Muria Kudus \\ Email: fanda.ayar@gmail.com \\ Supriyono \\ Fakultas Teknik, Program Studi Sistem Informasi \\ Universitas Muria Kudus \\ Email: supriyono.si.umk@gmail.com \\ Fajar Nugraha \\ Fakultas Teknik, Program Studi Sistem Informasi \\ Universitas Muria Kudus \\ Email: fajar.noeg@gmail.com
}

\begin{abstract}
ABSTRAK
Kuliah Kerja Nyata (KKN) merupakan salah satu kegiatan yang harus dilaksanakan oleh semua mahasiswa Universitas Muria Kudus untuk menerapkan pengetahuan yang telah diperoleh selama duduk di bangku perkuliahan serta sebagai wujud nyata pengabdian kepada masyarakat. Untuk membantu kelancaran kegiatan KKN tersebut diperlukan pengelolaan data yang terkait dengan kegiatan KKN. Tujuan dari penelitian ini adalah menghasilkan sistem informasi yang berguna dalam menangani proses pendaftaran KKN, pembagian kelompok KKN, mengetahui waktu dan tempat pelaksanaan $\mathrm{KKN}$, mengetahui dosen pembimbing lapangan dan melihat penilaian hasil KKN dan sebagai sarana mempublikasikan informasi yang berhubungan dengan kegiatan KKN melalui sebuah sistem informasi. Hasil dari rancang bangun ini adalah sebuah sistem informasi yang digunakan untuk pengelolaan kegiatan $\mathrm{KKN}$, manfaat sistem informasi $\mathrm{KKN}$ ini diharapkan dapat meningkatkan pelayanan dalam pengelolaan kegiatan KKN serta memperlancar proses administrasi kegiatan KKN menjadi lebih cepat dan akurat. Sistem ini dirancang menggunakan pemodelan UML (Unified Modeling Language), sedangkan bahasa pemrograman yang digunakan adalah PHP dan database MySQL.
\end{abstract}

Kata kunci: sistem informasi, kuliah kerja nyata, pelayanan

\begin{abstract}
Field Work Experience is one of the activities to be implemented by all students at the University of Muria Kudus to apply the knowledge that has been gained during lectures and sit on the bench as a tangible manifestation of community service. To assist the smooth operation of the community work required management of data related to the activities of the real working class. The purpose of this research is to produce information systems that are useful in dealing with the registration process, the division of the group, find out the time and place of execution, a field supervisor know and see the assessment results and as a means of publicizing information related to the activities of their community work through an information system. Results of this design is an information system that is used for the management of community work activities, benefits informasiini system is expected to improve services in the management of community work activities and facilitate the administrative process becomes faster and more accurate. The system is designed using modeling UML (Unified Modeling Language), while the programming language used is PHP and the MYSQL database.
\end{abstract}

Keywords: information system, Field Work Experience, service.

\section{PENDAHULUAN}

Dewasa ini, Kebutuhan akan informasi menjadi suatu kebutuhan primer dihampir berbagai bidang antara lain bidang pendidikan, budaya, pemerintah maupun masyarakat pada umumnya. Hal ini dapat dilihat dari meningkatnya kebutuhan akan informasi yang mendukung di berbagai aktivitas kegiatan seperti halnya kegiatan kuliah kerja nyata $(\mathrm{KKN})$. Pengelolaan data dalam pelaksanaan kegiatan $\mathrm{KKN}$ sangat memerlukan dokumentasi 
data yang baik serta harus dapat mengakomodir beberapa proses yang diperlukan dalam pelaksanaan kegiatan $\mathrm{KKN}$, diantaranya pengelolaan data mengenai pendaftaran KKN, pembagian kelompok KKN, pembagian waktu dan tempat pelaksanaan KKN, pembagian dosen pembimbing lapangan (DPL) serta proses penilaian hasil KKN.

Kendala dari penyampaian informasi yang terkait dengan pelaksanaan kegiatan KKL tersebut banyak terjadi, bagi mahasiswa yang ingin mengetahui informasi mengenai KKN, baik mengenai persyaratan, pendaftaran, waktu, dan tempat pelaksanaan masih dirasakan kurang memadai. Untuk mengatasi masalah-masalah di atas diperlukan suatu alternatif dengan membuat sistem informasi kuliah kerja nyata agar dapat memberikan informasi dan menyajikan informasi yang berkaitan dengan kegiatan KKN.

\section{LANDASAN TEORI}

\subsection{Sistem Informasi}

Sistem informasi dapat didefinisikan sebagai berikut :

1. Suatu sistem yang dibuat oleh manusia yang terdiri dari komponen-komponen dalam organisasi untuk mencapai suatu tujuan yaitu menyajikan informasi.

2. Sekumpulan prosedur organisasi yang pada saat dilaksanakan akan memberikan informasi bagi pengambil keputusan dan atau untuk mengendalikan informasi.

3. Suatu sistem didalam suatu organisasi yang mempertemukan kebutuhan pengolahan transaksi, mendukung operasi, bersifat manajerial, dan kegiatan strategi dari suatu organisasi dan menyediakan pihak luar tertentu dengan laporan-laporan yang diperlukan [1].

\subsection{Kuliah Kerja Nyata (KKN)}

Kuliah Kerja Nyata (KKN) adalah sebagai salah satu wahana bagi mahasiswa untuk mengaplikasikan teoriteori yang dimilikinya ke dalam sebuah wujud nyata pengabdian kepada masyarakat. KKN juga merupakan bentuk konkrit dari pengalaman yang mencakup pendidikan, penelitian, dan pengabdian kepada masyarakat [2]. Dengan adanya KKN ini, mahasiswa diharapkan dapat mengaktualisasikan disiplin ilmu yang masih dalam tataran teoritis dengan bentuk pengabdian dan pendampingan langsung kepada masyarakat,disamping penelitian yang dilakukan sebagai usaha pengmbangan ilmu yang didapat sebelumnya. Selain itu, KKN juga memiliki keterampilan dalam mengatasi dan menyelesaikan masalah-masalah yang terjadi ditengah masyarakat sebagai media untuk belajar membangun hubungan yang integral dalam masyarakat, sebagai obbyek utama yang akan dihadapi kelak setelah menyelesaikan studi.

\section{TINJAUAN PUSTAKA}

Penelitian yang berjudul "Perancangan Sistem informasi Kuliah Kerja Nyata Universitas Lampung Berbasis Web" [3], dalam penelitian ini dilatarbelakangi oleh permasalahan kurangnya koordinasi antara pihak desa tempat KKN berlangsung dengan kampus. Salah satu untuk mengoptimalkan peran mahasiswa dalam kegiatan KKN adalah dengan mengetahui kebutuhan desa tersebut sehingga dapat dibentuk tim dengan berbagai kemampuan yang dibutuhkan untuk melaksanakan program kerja yang direncanakan. Berdasarkan permasalahan tersebut dalam penelitian ini menitikberatkan pada pembagian tim atau kelompok mahasiswa KKN. Perancangan sistem menggunakan Data Flow Diagram, untuk penerapan web based merupakan implementasi konsep teknologi informasi pada pambagian tim mahasiswa KKN.

Penelitian dengan judul "Pengembangan Aplikasi Untuk Penentuan Divisi KKN Alternatif berbasis Sistem Informasi Geografis di LPM Universitas Ahmad Dahlan Yogyakarta" [4], dalam penelitian ini mengangkat permasalahan mengenai perencanaan dan pembagian KKN unit alternatif membutuhkan waktu yang relatif lama sehingga diperlukan sebuah sistem atau aplikasi yang mampu menentukan divisi KKN alternatif berbasis Sistem Informasi Geografis. Aplikasi yang dibangun dapat melakukan pengelompokan unit kedalam divisi dan mendistribusikan DPL dalam divisi tersebut serta membantu untuk melakukan pencarian lokasi baru KKN alternatif.

\section{METODOLOGI PENELITIAN}

\subsection{Metode Rekayasa Perangkat Lunak}

Rekayasa Perangkat Lunak (RPL) secara umum disepakati sebagai terjemahan dari istilah Software Engineering. Rekayasa Perangkat Lunak adalah pembangunan dengan menggunakan prinsip atau konsep rekayasa 
dengan tujuan menghasilkan perangkat lunak yang bernilai ekonomi yang dipercaya dan bekerja secara efisien menggunakan mesin [5]. Tahap-tahap dalam Model Waterfall, yaitu :

1. Analisis kebutuhan perangkat lunak merupakan proses pengumpulan kebutuhan secara intensif untuk menspesifikasikan kebutuhan perangkat lunak agar dipahami oleh user.

2. Desain adalah proses multilangkah yang fokus pada desain pembuatan program perangkat lunak termasuk struktur data, arsitektur perangkat lunak, representasi antarmuka dan prosedur pengkodean.

3. Pengkodean, desain diterjemahkan ke dalam program perangkat lunak.

4. Pengujian, proses yang dilakukan untuk meminimalisir kesalahan (error) dan memasukkan keluaran yang dihasilkan sesuai dengan keinginan.

5. Pemeliharaan, mengulangi proses pengembangan mulai dari analisis spesifikasi untuk perubahan perangkat lunak yang sudah ada, tapi tidak untuk membuat perangkat lunak baru.

\subsection{Metode Perancangan Sistem}

Dalam Perancangan Sistem menggunakan pemodelan proses untuk mengilustrasikan aktivitas-aktivitas yang dilakukan dan bagaimana data berpindah diantara aktivitas-aktivitas tersebut. Cara untuk merepresentasikan proses model dengan menggunakan UML (Unified Modeling Language). UML merupakan sistem arsitektur yang bekerja dengan Object Oriented Arcitechture Design (OOAD) dengan satu bahasa yang konsisten untuk menentukan, visualisasi, mengkontruksi, dan mendokumentasikan artifact yang terdapat dalam sistem software [6].

\subsection{Metode Pengumpulan Data}

Metode pengumpulan data yang digunakan dalam penelitian ini adalah sebagai berikut:

1. Metode Observasi, pengamatan yang dilakukan secara sengaja dan sistematis untuk kemudian dilakukan pencatatan dengan menggunakan dan mempelajari praktek-praktek pelaksanaan di tempat penelitian meliputi Proses pendaftaran KKN, pembagian kelompok KKN, pembagian waktu dan tempat pelaksanaan KKN, pembagian dosen pembimbing lapangan (DPL) serta proses penilaian hasil KKN.

2. Metode Kepustakaan, untuk memperluas cakrawala pandang, maka perlu membaca buku yang sesuai dengan permasalahan penulis, sebagai bahan pertimbangan untuk mendapatkan data sekunder yang mengacu pada literatur, buku, diktat, catatan yang dapat menunjang penyusunan penelitian ini.

3. Metode Wawancara, untuk mendapatkan masukan berkenaan dengan sistem informasi yang ada maka penulis menanyakan yang berkaitan dengan permasalahan yang terjadi dalam pengelolaan kegiatan KKN.

4. Metode Dokumentasi, metode ini digunakan untuk mengetahui proses-proses yang pernah dilakukan oleh lembaga pengelola kegiatan KKN Universitas yaitu Lembaga Pengabdian Kepada Masyarakat (LPM) Universitas Muria Kudus.

\section{HASIL DAN PEMBAHASAN}

\subsection{Analisa masalah}

Dari hasil penelitian yang telah dilaksanakan di Lembaga Pengabdian Kepada Masyarakat (LPM), maka hasil yang dapat disimpulkan adalah selama ini informasi Kuliah Kerja Nyata pada Universitas Muria Kudus masih dilakukan secara manual antara lain dalam proses pendaftaran $\mathrm{KKN}$, pembagian kelompok KKN, informasi mengenai waktu dan tempat pelaksanaan $\mathrm{KKN}$, pembagian dosen pembimbing lapangan dan proses penilaian hasil KKN, masih disampaikan dalam bentuk cetak (print- out) yang ditempel pada papan pengumuman. Kendala dari penyampaian informasi tersebut banyak terjadi dan bagi mahasiswa yang ingin mengetahui informasi mengenai KKN, baik mengenai persyaratan, pendaftaran, waktu, dan tempat pelaksanaan masih dirasakan kurang untuk mendapatkan informasi.

Untuk mengatasi masalah-masalah di atas diperlukan suatu alternatif lain dengan membuat sistem informasi. Bagi mahasiswa, khususnya dapat memberikan informasi dan menyajikan data-data yang berkaitan dengan persyaratan, waktu, dan tempat pelaksanaan,sehingga mempermudah bagi mahasiswa dapat mengetahui informasi yang terkait dengan pelaksanaan kegiatan KKN.

\subsection{Analisis Kebutuhan Data dan Informasi}

Untuk membangun sebuah sistem dibutuhkan adanya masukan berupa data yang nantinya akan diproses oleh sistem sehingga dapat memberikan informasi yang bermanfaat kepada penggunanya. Kebutuhan data dan informasi untuk sistem informasi Kuliah Kerja Nyata (KKN) berbasis web adalah :

a. Data yang dibutuhkan antara lain : data mahasiswa, data lokasi, data kelompok, data dosen. 
b. Informasi yang akan dihasilkan dalam penelitian ini antara lain: informasi pendaftaran, Pelaksanaan, kelompok KKN, lokasi KKN, DPL, serta informasi kegiatan pembekalan KKN.

\subsection{Bisnis Use Case Diagram}

Bisnis Use Case diagram merupakan sebuah alat untuk mengidentifikasi dan menggambarkan keseluruhan proses bisnis yang berpengaruh di dalam sistem [6]. Adapun penggambaran use case diagram dari Sistem Informasi Kuliah Kerja Nyata (KKN) secara detail dapat dijelaskan pada gambar 1.

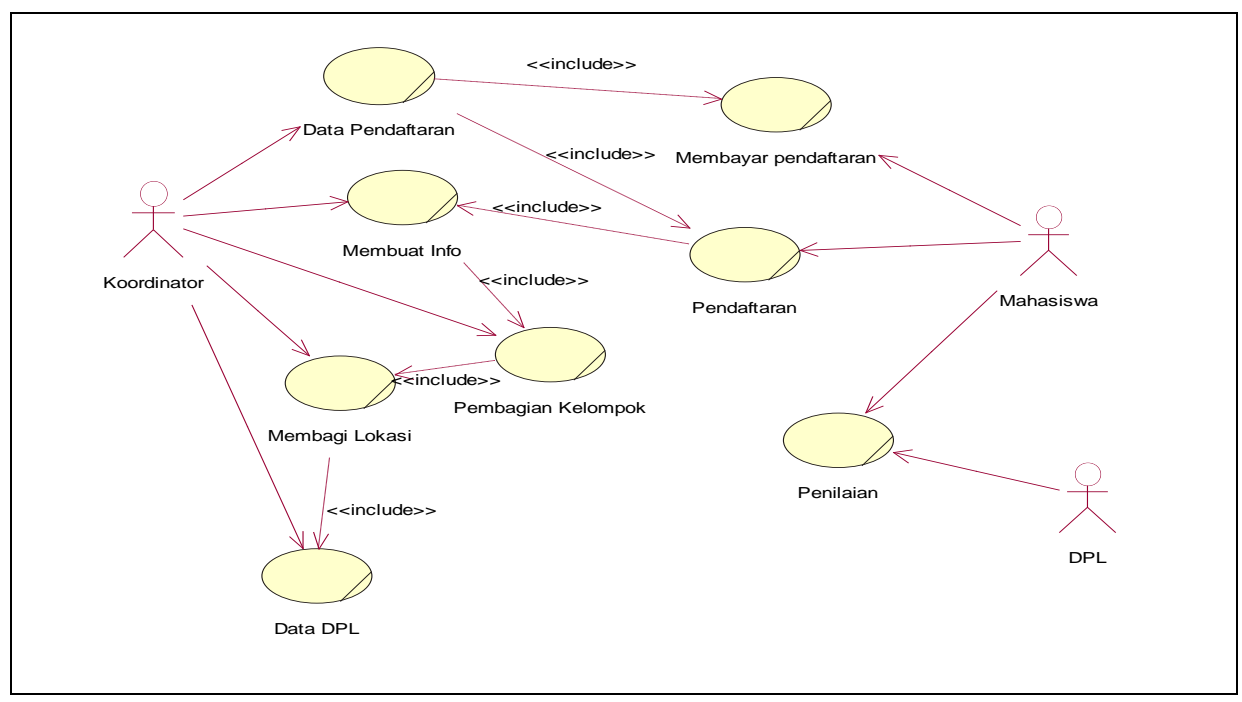

Gambar 1. Bisnis Use Case sistem informasi KKN

\subsection{Use Case Diagram}

Use case atau diagram use case menjelaskan manfaat sistem jika dilihat menurut pandangan orang yang berada diluar sistem (actor). Diagram ini menunjukkan fungsionalitas suatu sistem atau kelas dan bagaimana sistem berinteraksi dengan dunia luar [6]. Adapun penggambaran use case diagram dari Sistem Informasi Kuliah Kerja Nyata $(\mathrm{KKN})$ secara detail dapat dijelaskan pada gambar 2.

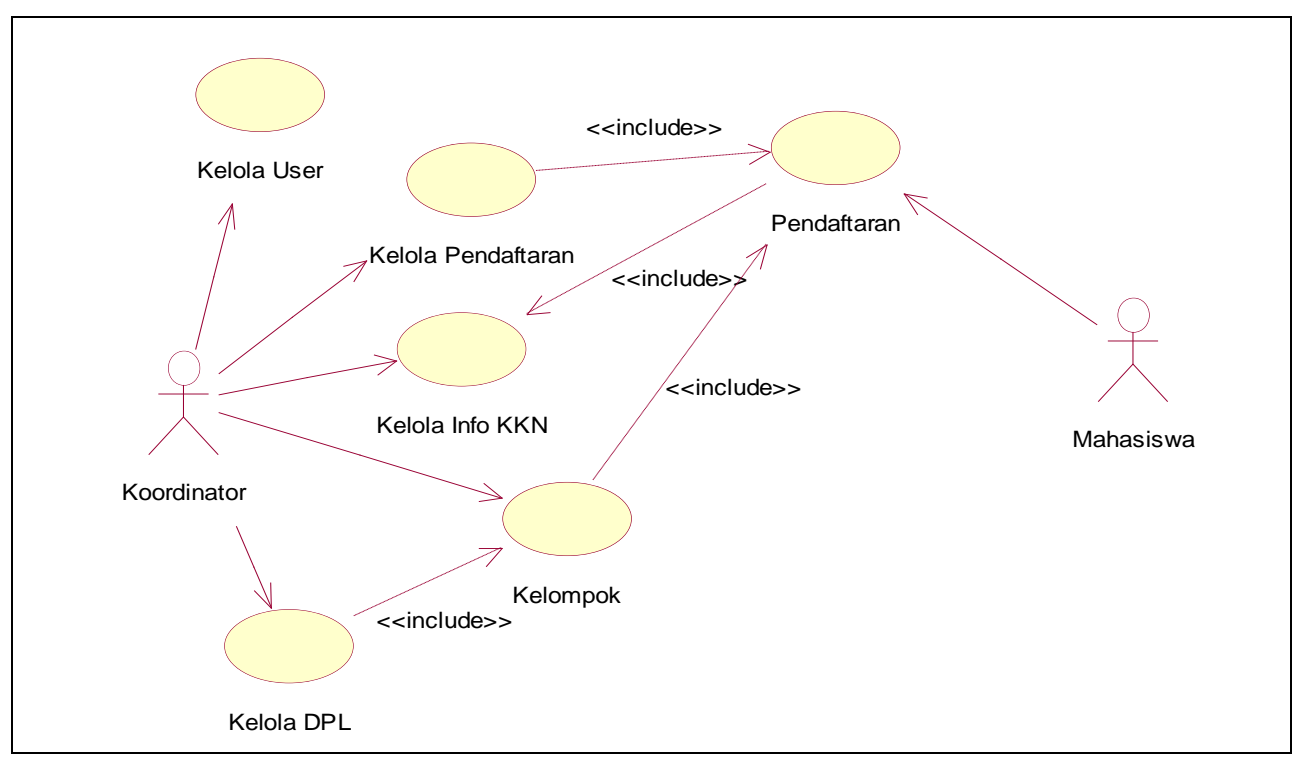

Gambar 2. Use Case diagram sistem informasi KKN 


\subsection{Class Diagram}

Gambar 3 menunjukan hubungan asosiasi setiap class pada sistem informasi KKN.

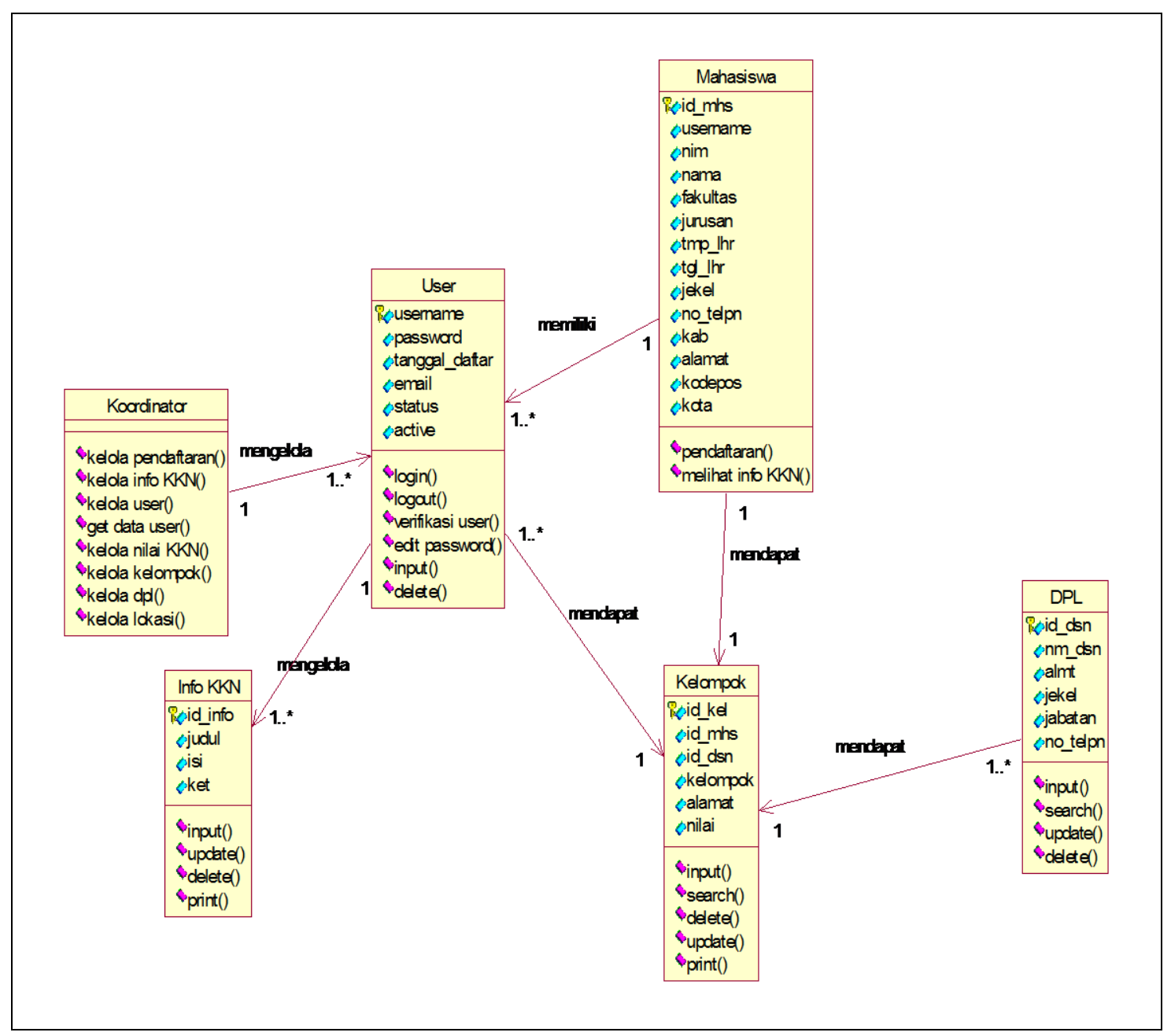

Gambar 3. Class diagram sistem informasi KKN

\subsection{Perancangan Basis Data}

Sebuah sistem informasi tidak akan lepas dari database atau basis data, basis data (atau database) adalah kumpulan terorganisasi dari data-data yang berhubungan sedemikian rupa sehingga mudah disimpan, dimanipulasi, serta dipanggil oleh pengguna [7]. Database digunakan untuk menyimpan informasi atau data yang terintegrasi dengan baik di dalam komputer Untuk mengelola database diperlukan suatu perangkat lunak yang disebut DBMS (Database Management System). DBMS merupakan suatu sistem perangkat lunak yang memungkinkan user (pengguna) untuk membuat, memelihara, mengontrol, dan mengakses database secara praktis dan efisien. Dengan DBMS, user akan lebih mudah mengontrol dan memanipulasi data yang ada. Sedangkan RDBMS atau Relationship Database Management System merupakan salah satu jenis DBMS yang mendukung adanya relationship atau hubungan antar tabel. Adapun tabel-tabel yang terbentuk berdasarkan kebutuhan data dan informasi dalam penelitian ini adalah sebagai berikut:

1. Tabel User

Tabel 1 ini adalah tabel yang berfungsi untuk menyimpan data user atau pengguna, tabel 1 nantinya akan menyimpan dan memberikan informasi user pada sistem informasi KKN, susunan dari tabel ini adalah sebagai berikut: 
Tabel 1. Tabel User

\begin{tabular}{lll}
\hline Field & Type Data & Size \\
\hline username & Varchar & 20 \\
password & Varchar & 20 \\
Nama_lengkap & Varchar & 60 \\
email & Varchar & 50 \\
status & Varchar & 20 \\
aktif & Enum & 'Y','N' \\
\hline
\end{tabular}

2. Tabel Mahasiswa

Tabel 2 berfungsi sebagai tabel untuk menyimpan data mahasiswa pendaftar kegiatan KKN, adapun susunan dari tabel 2 adalah sebagai berikut:

Tabel 2. Tabel Mahasiswa

\begin{tabular}{lll}
\hline Field & Type Data & Size \\
\hline Id_mhs & Varchar & 12 \\
Username & Varchar & 60 \\
Nim & Varchar & 20 \\
Nama & Varchar & 50 \\
Fakultas & Varchar & 30 \\
Tmp_lhr & Varchar & 50 \\
Tgl_lhr & date & - \\
Jekel & enum & L/P \\
No_telpn & Varchar & 12 \\
Kab & Varchar & 50 \\
Alamat & Text & 100 \\
Kodepos & Varchar & 12 \\
Kota & Varchar & 30 \\
\hline
\end{tabular}

3. Tabel DPL

Tabel 3 berfungsi sebagai tabel untuk menyimpan data DPL, adapun susunan dari tabel 3 adalah sebagai berikut:

Tabel 3. Tabel DPL

\begin{tabular}{lll}
\hline Field & Type Data & Size \\
\hline Id_dsn & Varchar & 5 \\
Nama & Varchar & 60 \\
Alamat & Text & - \\
Jekel & Varchar & 20 \\
jabatan & Varchar & 20 \\
No_telpn & Int & 12 \\
\hline
\end{tabular}

4. Tabel kelompok

Tabel 4 berfungsi sebagai tabel yang digunakan untuk menyimpan data kelompok pada kegiatan KKN, adapun susunan dari tabel 4 adalah sebagai berikut:

Tabel 4. Tabel Kelompok

\begin{tabular}{lll}
\hline Field & Type Data & Size \\
\hline Id_kel & Varchar & 10 \\
Id_mhs & Varchar & 12 \\
Kelompok & Varchar & 60 \\
Id_dsn & Varchar & 12 \\
Alamat & Text & 100 \\
Nilai & Varchar & 12 \\
\hline
\end{tabular}




\section{Tabel Info}

Tabel 5 berfungsi sebagai tabel untuk menyimpan informasi-informasi yang terkait dengan kegiatan KKN, adapun susunan dari tabel 5 adalah sebagai berikut:

Tabel 5. Tabel info

\begin{tabular}{lll}
\hline Field & Type Data & Size \\
\hline Id_info & Integer & 11 \\
Jdl_info & Text & - \\
Isi_info & Text & - \\
Tgl_posting & Date & - \\
\hline
\end{tabular}

\section{PERANCANGAN ANTARMUKA}

Gambar 4 menunjukan halaman user dari sistem informasi KKN. Dimana terdapat beberapa menu antara lain, menu pendaftaran, menu profil, menu kelompok dan menu nilai.

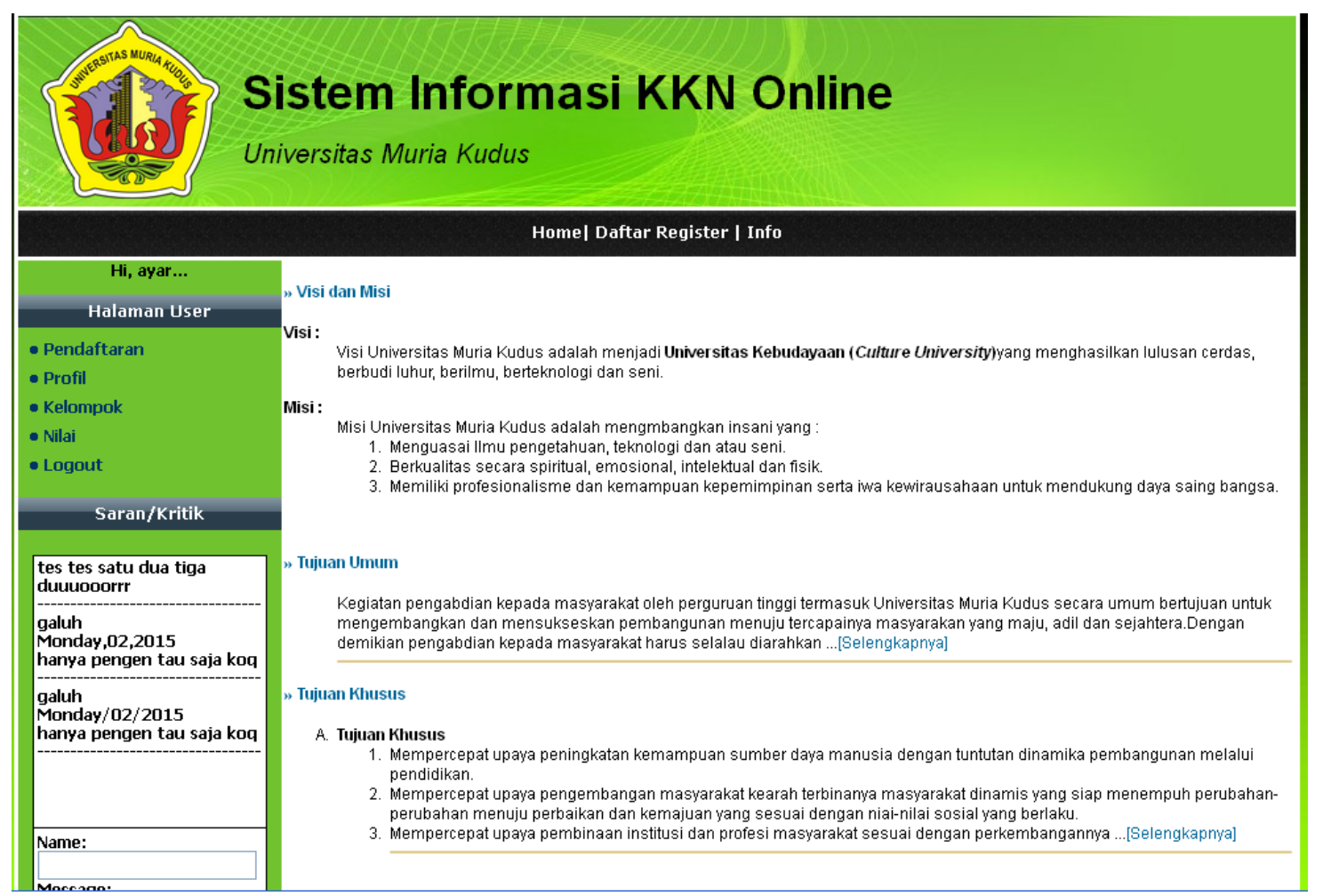

Gambar 4. Halaman user sistem informasi KKN

\section{KESIMPULAN}

Dari hasil penelitian dan pembahasan yang telah dilakukan terhadap sistem informasi kuliah kerja nyata $(\mathrm{KKN})$ yang dikembangkan untuk lembaga pengabdian kepada masyarakat (LPM) Universitas Muria Kudus, maka didapat suatu kesimpulan sebagai berikut :

1. Sistem informasi KKN memerlukan pendataan anatara lain data mahasiswa, data dosen pembimbing lapangan (DPL), data lokasi KKN.

2. Proses yang yang dilakukan antara lain pendaftaran, pembayaran, pembagian DPL, pembagian kelompok, penilaian.

3. Informasi yang dihasilkan meliputi laporan pendaftaran dan pembayaran, kelompok KKN, lokasi KKN, pembagian DPL, dan informasi hasil penilaian KKN. 


\section{DAFTAR PUSTAKA}

[1] Ladjamuddin, A.B. (2005). Analisis dan Desain Sistem Informasi, Yogyakarta : Graha Ilmu.

[2] T. Penyusun, (2014) .Panduan Kuliah Kerja Nyata Universitas Muria Kudus.

[3] Taufiq R, dkk. 2013. "Perancangan Sistem Informasi Kuliah Kerja Nyata Universitas Lampung Berbasis Web”. Jurnal Informatika dan Teknik Elektro Terapan. Volume 1. Nomor 3.

[4] Tedy S, Prasetyo. 2009. "Pengembangan Aplikasi Untuk Pemetaan Divisi KKN Alternatif berbasis Sistem Informasi Geografis di LPM Universitas Ahmad Dahlan Yogyakarta". Jurnal Informatika, Volume 3. Nomor 1.

[5] Shalahuddin, Muhammad dan Rosa Ariani S. (2011). Modul Pembelajaran Rekayasa Perangkat Lunak Trstruktur dan Berientasi Objek, Bandung: Modula.

[6] Suhendar, A. dan Gunadi, H. (2002). Visual Modelling Menggunakan UML dan Rational Rose, Bandung: Informatika.

[7] Nugroho, Adi. (2011). Perancangan dan Implementasi Sistem Basis Data, Yogyakarta: Andi. 